\title{
Urban Heat Island studies: Current status in India and a comparison with the International studies
}

\author{
$\mathrm{K}_{\text {Veena }}{ }^{1,2, *}, \mathrm{~K} \mathrm{M}$ Parammasivam $^{1}$ and $\mathrm{T} \mathrm{N}_{\text {Venkatesh }}{ }^{2}$ \\ ${ }^{1}$ Madras Institute of Technology, Chennai 600 044, India. \\ ${ }^{2}$ CTFD Division, CSIR-National Aerospace Laboratories, Bengaluru 560 017, India. \\ *Corresponding author.e-mail: aarya.vjs@gmail.com
}

MS received 20 May 2019; revised 17 October 2019; accepted 14 December 2019

Urbanization has resulted in many critical issues like increase in pollution levels, sudden climatic changes and the rise of temperature in the urban area, that is the formation of Urban Heat Islands (UHI). As the density of population rises, most of the land areas are being converted into cities and cities grows very rapidly. Due to the UHI effect, the cities are becoming hotter day by day. In India, all the metropolitan cities are victims of UHI effect and the severity of heat formation, necessitates research in this area. The present paper evaluates the trends of UHI studies in Indian cities and its out reach till 2018. Heat Island classification, methods of studying UHI in India and their limitation are discussed. Eventually a comparison of new trends of UHI studies in the world and where India lacks its growth in UHI research are included in this paper. One of the findings is that numerical modelling studies are very limited in India in this field and more focus in this area is required.

Keywords. Urbanization; Urban Heat Islands; numerical modelling.

\section{Introduction}

The world today is facing many environmental problems such as global warming, air pollution, extinction of animal and plant species, contamination of soil and water bodies and sudden climatic changes. Urbanization has been attributed to these environmental issues globally for past two decades. Population increases along with the economic growth and consumption of fossil fuels is having a linear relation with the population rise. Increased consumption of fossil fuels finally gives the by-products for greenhouse gas (GHG) effect. Even though around three by fourth of earth's surface area is covered by water, still the world faces scarcity of potable water. The water bodies are getting contaminated due to dumping of urban garbage, oil spills, commercial and industrial waste, etc. and as a consequence, the marine plants and animals are in the verge of endanger. The unanticipated climatic changes we are facing today is never due to natural processes, but only due to the unnecessary intervention of the human activities as a part of urbanization. Increase in fuel usage, waste disposal, high level usage of concrete, deforestation and greenhouse gas emission leads to the urban heat islands, global warming, flood, heavy rain fall, melting of polar ice caps and many more. These climatic effects have more harmful outcomes such as restructuring of ecosystems, inhibition to the growth of animals and plants, increase in epidemics, rise in human health issues, etc. Therefore, understanding the causes of these climatic problems and finding solution for these have become part of every country's research and 
developmental programmes. Rise in temperature is a serious issue faced by the world due to fast growth in conversion of land areas into cities. The UHI effect is mainly caused by reduced sky view factors, materials with high heat capacity, anthropogenic heat, lack of evapotranspiration and reduced turbulent convection as per Blocken (2015) and Nakata-osaki et al. (2015). According to them, UHI influencing parameters are wind, solar radiation, anthropogenic heat, sky view factor, urban canopy, building material, building ventilation, type of land surfaces, etc. Changes in these parameters are considered for evaluating the heat intensity at a particular location.

It was Luke Howard, who pioneered the microclimatic study when history of urban climatology is examined. His contributions are evident in his book 'The Climate of London, deduced from Meteorological Observations, made at different places in the Neighbourhood of the Metropolis', Vol I, published in 1818 (Luke 1818). Howard conducted experiments to study the climate of a city and his findings are the base for the researchers who are concerned with the urban climatic study (Mills 2008, 2009, 2014). In 1937, Albert Kratzer published the first edition of his book 'The climate of Cities (Das Stadtklima)' (Kratzer 1937, 1956) which gives motivation for urban climate study. There are many followers afterwards including Helmut E Landsberg the author of the book 'The Urban Climate', published in 1981 (Landsberg 1981). The modern era or history of urban climatic study was initiated by Tim Oke. In the paper, Oke (2006) describes eight modes of investigation or practice employed in the Urban Climatology: Conceptualization, Theorization, Field observation, Modelling (statistical, scale and numerical), Validation of models, Application in urban design and planning, Impact assessment (post-implementation) and Policy development and modification. As it was initiated from the conceptual form to theoretical form, the modern climatic work is in the stage of well representing all the first four modes of investigation. There are well established models, but still validation of models is in its developmental stage, which requires prime importance. According to Oke, proper communication between all the eight modes are essential for the functioning of urban climatology study with minimal errors. The challenge lies in transferring the acquired scientific knowledge into practice through proper designing and planning as well as modifying the existing policies accordingly. He believes the future prospectus is in connecting the scattered researchers to reduce the solitude and engaging them for an effective communication (Mills 2014).

\section{Increasing Heat Island formation in Indian cities}

Urbanization that results in the formation of heat pockets or UHI which rises near surface air temperature has become a serious issue in the Indian cities also. As cities are increasing in its size, the local climate also gets modified accordingly. As per Sharma and Bharat (2009), the causes of change in the city climate is due to albedo, changes in the shape of the city and the sky view factor related to that, air pollution and anthropogenic heat due to human activities, industries, vehicles, etc.

The reports showed that mean maximum heat island intensity observed in Chennai city has been $2.48^{\circ} \mathrm{C}$ during summers and $3.35^{\circ} \mathrm{C}$ during winters. A study carried out in IISc, Bangalore (Ramachandra and Kumar 2010) showed an increase of nearly $2^{\circ}-2.5^{\circ} \mathrm{C}$ in air temperatures in the past decade and it also showed a growth of $632 \%$ in urban area of Bangalore from 1973 to 2009. Another study conducted by IIT Delhi in Delhi city has found the maximum and minimum heat island intensity to reach temperatures of $8.3^{\circ}$ and $4.7^{\circ} \mathrm{C}$, respectively. A rise of $1^{\circ}-6^{\circ} \mathrm{C}$ has been shown in land surface temperatures from the year 1999 to 2006 in the studies conducted in Pune. The reports show internationally the maximum UHI intensity recorded is as high as $12^{\circ}$ and in India the maximum observed UHI intensity is $8-9^{\circ} \mathrm{C}$. So the after effect of heat island formation is that there is notable increase in energy and water consumption, increased emission of pollutants to the atmosphere leading into greenhouse effect, heat-related discomfort in health and life, degradation in water quality of streams, rivers and other water bodies (Jain and Sarkar 2017). Jain and Sarkar (2017) gave the strategies for reducing the UHI effect as by improving the vegetation cover, constructing green walls and roofs, increasing the reflectivity (albedo) and emissivity of the building material, utilising passive cooling methods in buildings and by reducing the anthropogenic heat production sources. Lack of public education and outreach is another reason for increase in heat intensity (Sharma and Bharat 2009). So policies should be 
made to balance the microclimate of cities and should be properly communicated to the public.

This research article is based on 37 papers collected on the UHI studies conducted in different parts of Indian cities. From the papers, it is found that majority of the studies are concentrated towards the capital city. About $30 \%$ of the collected papers include the heat island formation in Delhi area, and the causes and effects of it. After Delhi, Bangalore is the second city where the UHI studies are focussed more. Table 1 shows the yearwise list of papers collected and the corresponding cities of studies. The locations of UHI studies in India is marked in the map as shown in figure 1.

Based on the collected papers it can be deduced that in India UHI studies were initiated in the early 20th century.
Table 1 shows the list of studies carried out for finding the heat island formation in different parts of India from the year 2000 to 2018 . The first paper on heat island intensity found was based on the temperature increase in Pune, Maharashtra in the year 2000 (Deosthali 2000). As mentioned above, majority of the studies are concentrated on the capital city, New Delhi (Mohan et al. 2012; Pandey et al. 2012; Babazadeh and Kumar 2015; Aslam et al. 2017) and the other cities where UHI studies were carried out are Bangalore (Gopalakrishnan et al. 2003; Ramachandra and Kumar 2010; Ambinakudige 2011), Mumbai (Grover and Singh 2015; Mehrotra 2018), Chennai (Gopalakrishnan et al. 2003; Amirtham 2016), Pune (Deosthali 2000; Nesarikar-Patki and Raykar-Alange 2012), Hyderabad (Gopalakrishnan et al. 2003), Ahmedabad

Table 1. UHI studies in Indian cities.

\begin{tabular}{|c|c|c|c|}
\hline no. & Year & Study location & Paper \\
\hline 1 & 2000 & Pune, Maharashtra & Deosthali (2000) \\
\hline 2 & 2003 & Chennai, Bangalore, Hyderabad & Gopalakrishnan et al. (2003) \\
\hline 3 & 2006 & Visakhapatnam, Andhra Pradesh & Devi (2006) \\
\hline 4 & 2009 & Bhopal, Madhya Pradesh & Gupta et al. (2009) \\
\hline 5 & 2010 & Bangalore, Karnataka & Ramachandra and Kumar (2010) \\
\hline 6 & 2011 & Delhi & Mohan et al. (2011) \\
\hline 7 & 2011 & Delhi & Ahmad et al. (2011) \\
\hline 8 & 2011 & Bangalore, Karnataka & Ambinakudige (2011) \\
\hline 9 & 2012 & Delhi & Mohan et al. (2012) \\
\hline 10 & 2012 & Pune, Maharashtra & $\begin{array}{l}\text { Nesarikar-Patki and Raykar-Alange } \\
\text { (2012) }\end{array}$ \\
\hline 11 & 2012 & Delhi & Pandey et al. (2012) \\
\hline 12 & 2012 & Jaipur, Rajasthan & Gupta (2012) \\
\hline 13 & 2013 & Delhi & Mohan et al. (2013) \\
\hline 14 & 2014 & Kochi, Kerala & Thomas et al. (2014) \\
\hline 15 & 2014 & Guwahati, Assam & Borbora and Das (2014) \\
\hline 16 & 2015 & Bathinda, Punjab & Sharma and Pandey (2015) \\
\hline 17 & 2015 & Thiruchirappalli, Tamil Nadu & Kannamma and Sundaram (2015) \\
\hline 18 & 2015 & Delhi and Mumbai, Maharashtra & Grover and Singh (2015) \\
\hline 19 & 2015 & Delhi & Babazadeh and Kumar (2015) \\
\hline 20 & 2015 & Ahmedabad, Gujarat & Joshi et al. (2015) \\
\hline 21 & 2016 & Ernakulam, Kerala & Baby and Arya (2016) \\
\hline 22 & 2016 & Chennai, Tamil Nadu & Amirtham (2016) \\
\hline 23 & 2016 & Uttarakhand & Kumar and Singh (2016) \\
\hline 24 & 2016 & Ahmedabad, Gujarat & Goswami et al. (2016) \\
\hline 25 & 2016 & Bhubaneswar, Odisha & Swain et al. (2016) \\
\hline 26 & 2016 & Noida, Uttar Pradesh & Kikon et al. (2016) \\
\hline 27 & 2016 & Kanpur, Uttar Pradesh & Chakraborty et al. (2016) \\
\hline 28 & 2017 & Lucknow, Uttar Pradesh & Singh et al. (2017) \\
\hline 29 & 2017 & Delhi & Aslam et al. (2017) \\
\hline 30 & 2017 & Andhra Pradesh & Kumar et al. (2017a) \\
\hline 31 & 2018 & Mumbai, Maharashtra & Mehrotra (2018) \\
\hline 32 & 2018 & Kolkata, West Bengal & Ali Gazi and Mondal (2018) \\
\hline
\end{tabular}




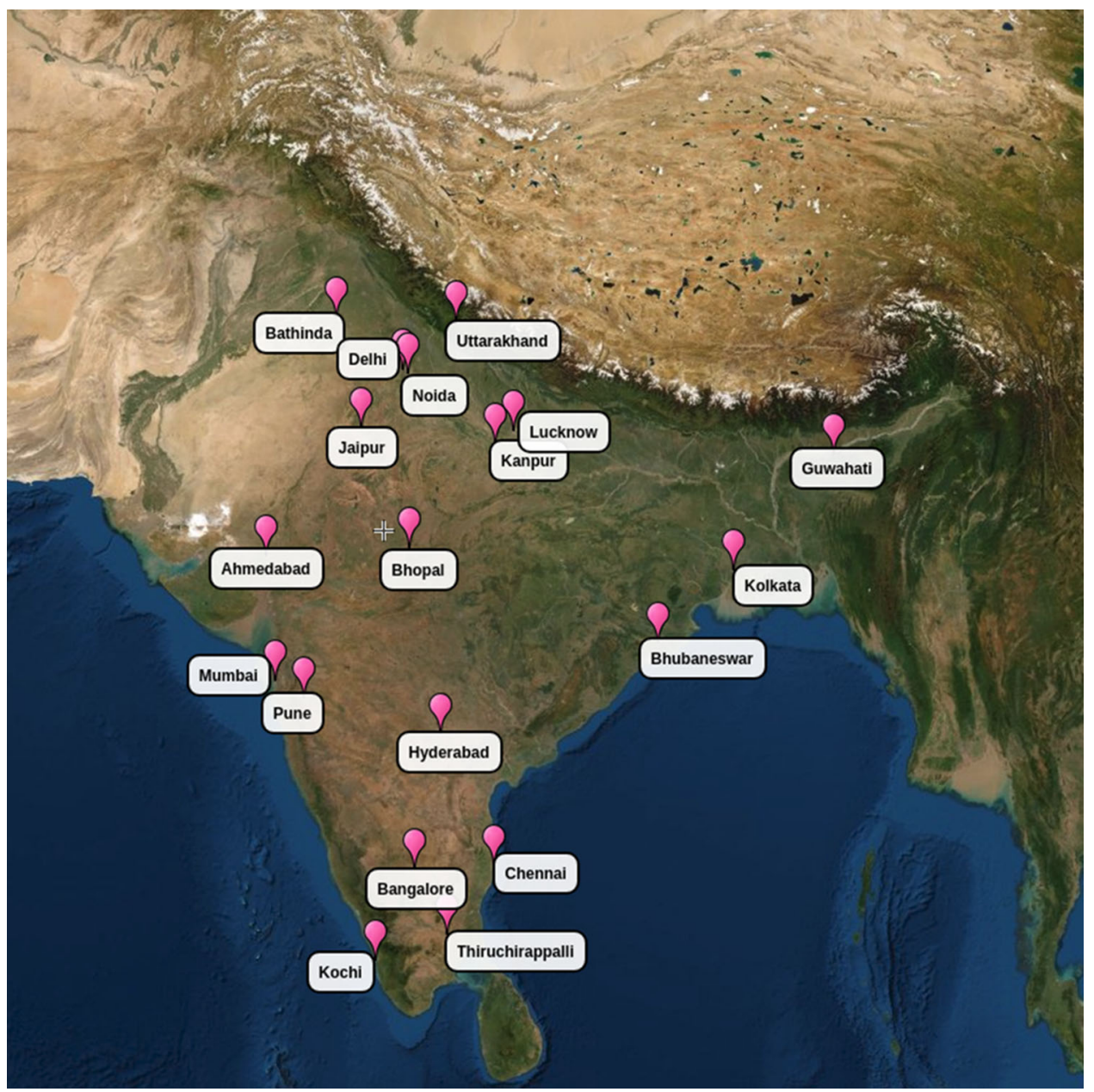

Figure 1. UHI studies conducted in Indian cities (map made using scribble maps).

(Joshi et al. 2015; Goswami et al. 2016), Visakhapatnam (Devi 2006), Ernakulam (Baby and Arya 2016; Thomas et al. 2014), Bhopal (Gupta et al. 2009), Bhubaneswar (Swain et al. 2016), Noida (Kikon et al. 2016), Kanpur (Chakraborty et al. 2016), Lucknow (Singh et al. 2017), Bathinda (Sharma and Pandey 2015), Guwahati (Borbora and Das 2014), Jaipur (Gupta 2012), Kolkata (Ali Gazi and Mondal 2018), Thiruchirappalli (Kannamma and Sundaram 2015) and Uttarakhand (Kumar and Singh 2016).

\section{Urban Heat Island definition and classification}

As per definition, the higher temperature observed in the cities in comparison with the surrounding rural area is called as Urban Heat Islands (Luke 1818). In similar way, an occasional lower temperature observed in cities are called Urban Cool
Islands. Urban Heat Island Intensity (UHII) is the index showing the presence of UHI. It is determined as the spatially averaged temperature difference between an urban and its surrounding rural area. But some reports are based on the difference between the air and surface temperatures. The UHI determined by comparing the 'mean' and 'maximum' temperature in between rural and urban area referred to as the 'mean' and 'maximum' UHI, respectively. The comparison time period varies from within a day, a few selected days, a month, a season and a year to even decades.

There are two main classifications of UHI: Atmospheric Heat Island (AHI) and Surface Heat Island (SHI). Most of the collected studies are based on SHI which employs the use of thermal satellite images, remote sensing, GIS tools, etc. SHI exists at all times. AHI is predominant at night and insignificant during day time. Fixed weather stations and mobile traverses are used to measure AHI intensity. Computational studies and experimental studies are more concentrated towards finding 
Table 2. Period of UHI study in various studies.

\begin{tabular}{|c|c|c|c|c|}
\hline $\begin{array}{l}\text { Sl. } \\
\text { no. }\end{array}$ & Paper & Study period & Duration & Variable \\
\hline 1 & Mohan et al. (2011) & $1968-2005$ & 37 years & $\mathrm{AT}$ \\
\hline 2 & Swain et al. (2016) & 2000-2014 & 15 years & LST \\
\hline 3 & Babazadeh and Kumar (2015) & 2000-2014 & 14 years & LST \\
\hline 4 & Kikon et al. (2016) & 2000-2013 & 13 years & LST \\
\hline 5 & Kumar et al. (2017b) & $2003-2014$ & 12 years & LST \\
\hline 6 & Goswami et al. (2016) & 2003-2014 & 12 years & $\mathrm{ST}$ \\
\hline 7 & Devi (2006) & - & 10 years & $\mathrm{ST}$ \\
\hline 8 & Ramachandra and Kumar (2010) & - & 10 years & $\mathrm{AT}, \mathrm{LST}$ \\
\hline 9 & Nesarikar-Patki and Raykar-Alange (2012) & 1999-2006 & 7 years & LST \\
\hline 10 & Thomas et al. (2014) & Jan 2011-Mar 2013 & 2 years and 3 months & $\mathrm{AT}$ \\
\hline 11 & Gopalakrishnan et al. (2003) & 2001,2002 & 2 years & $\mathrm{AT}, \mathrm{ST}$ \\
\hline 12 & Gupta et al. (2009) & 2006 & 1 year & $\mathrm{ST}$ \\
\hline 13 & Gupta (2012) & between 2001 and 2009 & - & $\mathrm{ST}$ \\
\hline 14 & Amirtham (2016) & May 2008 to Jan 2009 & 9 months & $\mathrm{AT}$ \\
\hline 15 & Pandey et al. (2012) & Nov and Dec of 2007-2010 & 8 months & $\mathrm{ST}$ \\
\hline 16 & Borbora and Das (2014) & May-Oct 2009 & 6 months & $\mathrm{AT}$ \\
\hline 17 & Shastri et al. (2017) & Mar-May and Dec-Feb & 6 months & LST \\
\hline 18 & Chakraborty et al. (2016) & Apr-Sept 2014 & 6 months & LST, AT \\
\hline 19 & Sharma and Pandey (2015) & Feb-Apr 2015 & 3 months & $\mathrm{ST}$ \\
\hline 20 & Aslam et al. (2017) & May and Dec 2013 & 2 months & $\mathrm{AT}$ \\
\hline 21 & Baby and Arya (2016) & Oct 2015 & 1 month & $\mathrm{AT}$ \\
\hline 22 & Deosthali (2000) & Apr 1970 & 1 month & $\mathrm{AT}$ \\
\hline 23 & Kumar et al. (2017a) & May 2016 & 1 month & LST \\
\hline 24 & Mohan et al. (2013) & 6-13 Mar 2010 & $7-8$ days & LST \\
\hline 25 & Mohan et al. (2012) & 25-28 May 2008 & 3 days & LST, AT \\
\hline 26 & Ambinakudige (2011) & 16 Mar 2000 and 09 Mar 2003 & 2 days & LST \\
\hline 27 & Grover and Singh (2015) & 05 May 2010 and 17 Apr 2010 & 2 days & LST \\
\hline 28 & Kannamma and Sundaram (2015) & May 2014 & 1 day & PET \\
\hline 29 & Ahmad et al. (2011) & 26 Jun 2006 & 1 day & LST \\
\hline 30 & Mehrotra (2018) & 20 Oct 2016 & 1 day & $\mathrm{ST}$ \\
\hline
\end{tabular}

LST $=$ Land Surface Temperature, AT $=$ Air Temperature, ST $=$ Surface Temperature, PET $=$ Physiological Equivalent Temperature.

AHI. AHI is again classified into two: Canopy Layer Heat Island (CLHI), present in the air between the roughness components with an upper boundary below the roof level and Boundary Layer Heat Island (BLHI), situated above CLHI.

Among the papers, more than $70 \%$ of the studies are related to Land Surface Temperature (LST) and Surface Temperatue (ST) analysis (i.e., Surface Heat Island study) and about $30 \%$ of studies are only on AHI. Table 2 shows the duration of UHI study in each paper along with the temperature variable used to define UHI and table 3 shows the magnitude of UHI intensity and the method of study adopted to calculate UHII.

Mohan et al. (2011) have found out the annual mean maximum temperature difference between the national capital region of India for a duration of
37 yrs. Here, when Mohan et al. (2011) found out the UHI intensity based on the annual mean and maximum temperature in the city, Swain et al. (2016) estimates UHI from the difference in the LST between urbanized and non-urbanized pixels from the MODIS data for the city of Bhubaneswar for a 15 yrs' period from 2000 to 2014. In Babazadeh and Kumar (2015) studies, UHI intensity during summer, winter and monsoon months are compared during the year from 2000 to 2014. It was found that intensity is high during summer season and the heat island intensity varies from $3^{\circ}$ to $8^{\circ} \mathrm{C}$. Likewise, Devi (2006), Ramachandra and Kumar (2010), Goswami et al. (2016), Kikon et al. (2016) studied UHI intensity in the cities of Noida, Ahmedabad, Vishakhapatnam and Bangalore, respectively, for longer duration of time that are in 
Table 3. UHII and its definition.

\begin{tabular}{|c|c|c|c|}
\hline Location and Paper & $\begin{array}{l}\text { Year of } \\
\text { UHI study }\end{array}$ & $\begin{array}{l}\text { UHII } \\
\left({ }^{\circ} \mathrm{C}\right)\end{array}$ & Method of calculation of UHI \\
\hline $\begin{array}{l}\text { Delhi } \\
\text { Ahmad et al. (2011) }\end{array}$ & 2006 & 9 & $\begin{array}{l}\text { Average of the maximum, minimum land surface temperature in the } \\
\text { centre of the city and surrounding rural areas along four different } \\
\text { profiles }\end{array}$ \\
\hline $\begin{array}{l}\text { Delhi } \\
\text { Pandey et al. (2012) }\end{array}$ & $2007-2010$ & $4-7$ & $\begin{array}{l}\text { Surface temperature of Delhi is compared to the surrounding rural areas } \\
\text { for two months of a few consecutive years }\end{array}$ \\
\hline $\begin{array}{l}\text { Delhi } \\
\text { Mohan et al. (2012) }\end{array}$ & 2008 & 8.3 & $\begin{array}{l}\text { Difference between highest temperature and lowest temperature } \\
\text { observed among all micrometeorological stations across the study area } \\
\text { for a particular time (day) }\end{array}$ \\
\hline $\begin{array}{l}\text { Delhi } \\
\text { Aslam et al. }(2017)\end{array}$ & 2013 & 2.2 & $\begin{array}{l}\text { The simple temperature gradient between the urban areas to its } \\
\text { surrounding rural areas for the given months }\end{array}$ \\
\hline $\begin{array}{l}\text { Kochi } \\
\text { Thomas et al. (2014) }\end{array}$ & $2011-2013$ & 4.6 & Near surface air temperature between urban and adjoining rural areas \\
\hline $\begin{array}{l}\text { Ernakulam } \\
\text { Baby and Arya (2016) }\end{array}$ & 2015 & 6 & $\begin{array}{l}\text { Change in peak temperature of a day between urban and semi-urban } \\
\text { areas }\end{array}$ \\
\hline $\begin{array}{l}\text { Chennai } \\
\text { Amirtham (2016) }\end{array}$ & 2008-2009 & 4.1 & $\begin{array}{l}\text { Air temperature difference between urban and rural areas for different } \\
\text { times of the day and in different seasons }\end{array}$ \\
\hline $\begin{array}{l}\text { Guwahati } \\
\text { Borbora and Das (2014) }\end{array}$ & 2009,2013 & 2.12 & $\begin{array}{l}\text { Temperature differences in half hourly data recording in the day and } \\
\text { night between highly urbanized and rural areas of the city }\end{array}$ \\
\hline $\begin{array}{l}\text { Bangalore } \\
\text { Ambinakudige (2011) }\end{array}$ & 2000,2003 & $1-7$ & $\begin{array}{l}\text { Difference in the mean temperature in the city core and the outgrowth } \\
\text { zone }\end{array}$ \\
\hline $\begin{array}{l}\text { Visakhapatnam } \\
\text { Devi }(2006)\end{array}$ & 2006 & $2-4$ & $\begin{array}{l}\text { The surface temperatures were plotted on a map of city and isotherms } \\
\text { were drawn to compare the warm core at the centre and surroundings }\end{array}$ \\
\hline $\begin{array}{l}\text { Ahmedabad } \\
\text { Goswami et al. (2016) }\end{array}$ & $2003-2014$ & 1.93 & $\begin{array}{l}\text { Land surface temperature difference at area of interest (city) with a } \\
\text { buffer zone of } 10 \mathrm{~km} \text { adjoining the area of interest }\end{array}$ \\
\hline $\begin{array}{l}\text { Bathinda } \\
\text { Sharma and Pandey (2015) }\end{array}$ & 2015 & $2-5$ & Surface temperature difference between selected urban and rural areas \\
\hline
\end{tabular}

years. But in some studies, the UHI intensity is estimated for a few months (Deosthali 2000; Pandey et al. 2012; Borbora and Das 2014; Sharma and Pandey 2015; Amirtham 2016; Baby and Arya 2016; Aslam et al. 2017; Shastri et al. 2017). The temperature isopleths at different times of a day and night is analyzed by Amirtham (2016) for urban as well as rural locations in and around Chennai Metropolitan Area to derive UHI intensity. In Pandey et al. (2012) paper, surface temperature in central parts of Delhi is compared with the surrounding rural areas for the months of November and December for years 2007, 2008, 2009 and 2010 to identify the formation of day time cool island and nocturnal urban heat island over Delhi. UHI intensity was also calculated for a few days as in the works of Ambinakudige (2011), Mohan et al. (2012, 2013), Grover and Singh (2015) and for even a single day as done by Ahmad et al. (2011), Kannamma and Sundaram (2015), Kumar et al. (2017a) and Mehrotra (2018).

Using the Landsat $5 \mathrm{TM}$, the built-up and vegetated areas temperature for Delhi on 5 May
2010 and for Mumbai on 17 April 2010 is analyzed by Grover and Singh (2015) for finding the presence of surface UHI. The maximum and minimum land surface temperature during day and night time in Delhi, Aligarh, Agra and surrounding rural areas are captured using MODIS LST product for 26th June 2006 by Ahmad et al. (2011) to evaluate UHII. In Mehrotra (2018) paper, Landsat 8 images are used to study LST pattern over Mumbai city for 20th October 2016.

Pandey et al. (2012) have done UHI studies based on SHI, by comparing the temperature of central city of Delhi to its surrounding rural areas. The method of study is by using the thermal mapping with MODIS satellite data for the months of November and December 2017-2010. Both day and night temperatures are measured which help to reveal heat islands as well as cool islands in the city. It was found that a maximum of $4-6^{\circ} \mathrm{C}$ cool island and maximum of $4-7^{\circ} \mathrm{C}$ heat islands are formed in the central parts of Delhi. Another study by Mohan et al. (2012) was also based on the national capital region where the seasonal and 
annual temperature trends were studied for mean, minimum and maximum temperatures for the past few decades using the data from meteorological stations.

Thomas et al. (2014) have tried measuring near surface air temperature using 12 mobile surveys for a duration from January 2011 to March 2013. It was observed that UHI is intense in winter than in summer in Kochi, Kerala. During winter, the heat intensity reached up to $4.6^{\circ} \mathrm{C}$ in pre-dawn and $3.7^{\circ} \mathrm{C}$ in the early night. A HOBO data logger (HOBO U10 Temp/RH), enclosed within a white perforated plastic box is deployed for measuring air temperature and relative humidity in the studies of Amirtham (2016). The UHI intensity was computed with the reference data available from Meteorological stations and they found that the maximum daytime temperatures were based on the urban morphology and the time at which the measurement location is exposed to incident solar radiation. In Chennai Metropolitan Area (CMA), existence of a cool island with a temperature difference of $10.4^{\circ} \mathrm{C}$ in summer and $3.7^{\circ} \mathrm{C}$ in winter was found at the urban core during daytime. At the same time, the night-time UHI was ranging from $3.6^{\circ} \mathrm{C}$ in summer to $4.1^{\circ} \mathrm{C}$ in winter.

Borbora and Das (2014) have studied the temperature variation in two sites in urban core and two sites away from the Guwahati city. Stationary loggers were used to conduct in-situ measurements for the period of May to October 2009 and from June to August 2013 using mobile measurements. The UHI found was $2^{\circ} \mathrm{C}$ and the day-time UHI intensity has reached up to $2.12^{\circ} \mathrm{C}$ and night-time UHI intensity up to $2.29^{\circ} \mathrm{C}$ for the entire period of study.

Joshi et al. (2015) estimated the surface heat islands for winter and summer season of 2013 for Ahmedabad city using Landsat satellite data and field data. The field data was collected from 50 selected points in the city and the building temperature was measured using Infrared Gun. From the studies, the UHI effect was found more in the Gujarat Industrial Development Corporation (GIDC) Naroda and the maximum temperature ranges between $35^{\circ}$ and $46^{\circ} \mathrm{C}$. In similar way, remote sensing and field surveys are only used by Singh et al. (2017) to find out the land surface temperature for Lucknow city of Uttar Pradesh. The period of study considered here was the difference in LST in the year 2002 and 2014 and it was calculated using Landsat satellite data. The results showed that the temperature in the central portion of Lucknow city has been increased from 2002 to
2014 and vegetation cover was fallen down during this period. According to them, remote sensing is an ideal method for analyzing UHI but the disadvantage is that it is hard to study the microlevel change in temperature as well as for the selection of pictures of same land surface and atmospheric conditions.

Surface temperature as well as air temperatures were calculated by Chakraborty et al. (2016) to identify the heat island formation in the Kanpur city of Uttar Pradesh. In the study, air temperature was measured using sensors and the surface temperature was derived from outgoing longwave radiative flux. Land surface temperature pattern were also estimated using MODIS TERRA satellite data system. SHI and CHI are evaluated using difference in surface temperatures and air temperatures, respectively. A recent study conducted in 2018 by Ali Gazi and Mondal (2018) for Kolkata Metropolitan Area is again using Landsat Satellite data. The UHI was identified based on LST for the last 17 yrs from 2000 to 2017 and the results show an increase in the trend of mean temperature of the area.

\section{Methods of UHI study}

Various methods have been developed to study UHI in different parts of the world. Ever since the start of identifying the importance of UHI study, theoretical/empirical based studies are available. But for a real time estimation of the presence of UHI and to find the ways of mitigating its effects, the methods used are observational, experimental and computational studies (Mirzaei et al. 2010).

Observational approaches include remote sensing, field measurements and meteorological weather station data (Sahu et al. 2014). Table 4 shows the methods employed in the UHI studies in Indian cities.

\subsection{Satellite data}

From table 4, it is found that more than $60 \%$ of the studies were done with the help of remote sensing by finding the LST data (Ambinakudige 2011; Ahmad et al. 2011; Nesarikar-Patki and RaykarAlange 2012; Babazadeh and Kumar 2015; Grover and Singh 2015; Kikon et al. 2016; Kumar and Singh 2016). The variants of LANDSAT satellite is majorly used to get land surface images for the UHI study. Commonly used LANDSAT versions and 
Table 4. UHI- method of study.

\begin{tabular}{|c|c|c|c|}
\hline no. & Paper & Variable & Method of study \\
\hline 1 & Kikon et al. (2016) & LST & Satellite Data \\
\hline 2 & Mohan et al. (2013) & LST & Satellite Data, Fixed station data \\
\hline 3 & Babazadeh and Kumar (2015) & LST & Satellite Data \\
\hline 4 & Kumar et al. (2017a) & LST & Instrumental Measurement \\
\hline 5 & Ambinakudige (2011) & LST & Satellite Data \\
\hline 6 & Gopalakrishnan et al. (2003) & $\mathrm{AT}, \mathrm{ST}$ & Mesoscale Models \\
\hline 7 & Devi (2006) & $\mathrm{ST}$ & Field survey \\
\hline 8 & Gupta et al. (2009) & $\mathrm{ST}$ & Satellite Data \\
\hline 9 & Gupta (2012) & $\mathrm{ST}$ & Satellite Data \\
\hline 10 & Deosthali (2000) & $\mathrm{AT}$ & Mobile survey \\
\hline 11 & Ahmad et al. (2011) & LST & Satellite Data \\
\hline 12 & Grover and Singh (2015) & LST & Satellite Data \\
\hline 13 & Ramachandra and Kumar (2010) & $\mathrm{AT}, \mathrm{LST}$ & Satellite Data \\
\hline 14 & Goswami et al. (2016) & $\mathrm{ST}$ & Satellite Data \\
\hline 15 & Swain et al. (2016) & LST & Satellite Data \\
\hline 16 & Kannamma and Sundaram (2015) & PET & Instrumental Measurement \\
\hline 17 & Mehrotra (2018) & $\mathrm{ST}$ & Satellite Data \\
\hline 18 & Kumar et al. (2017b) & LST & Satellite Data \\
\hline 19 & Pandey et al. (2012) & $\mathrm{ST}$ & Satellite Data \\
\hline 20 & Baby and Arya (2016) & $\mathrm{AT}$ & Instrumental Measurement \\
\hline 21 & Mohan et al. (2011) & $\mathrm{AT}$ & Fixed station data \\
\hline 22 & Borbora and Das (2014) & $\mathrm{AT}$ & Instrumental Measurement \\
\hline 23 & Aslam et al. (2017) & $\mathrm{AT}$ & Satellite Data, Fixed station data, Mesoscale model \\
\hline 24 & Thomas et al. (2014) & $\mathrm{AT}$ & Mobile survey, Fixed recording station \\
\hline 25 & Mohan et al. (2012) & LST, AT & Satellite Data, Field survey, Fixed station data \\
\hline 26 & Shastri et al. (2017) & LST & Satellite Data \\
\hline 27 & Sharma and Pandey (2015) & $\mathrm{ST}$ & Instrumental Measurement \\
\hline 28 & Nesarikar-Patki and Raykar-Alange (2012) & LST & Satellite Data \\
\hline 29 & Kumar and Singh (2016) & LST & Satellite Data \\
\hline 30 & Amirtham (2016) & $\mathrm{AT}$ & Fixed station data \\
\hline 31 & Singh et al. (2017) & LST & Satellite Data \\
\hline 32 & Joshi et al. (2015) & $\mathrm{ST}$ & Satellite Data, Field Data \\
\hline 33 & Ali Gazi and Mondal (2018) & LST & Satellite Data \\
\hline 34 & Chakraborty et al. (2016) & $\mathrm{ST}, \mathrm{AT}$ & Fixed station data, Mobile survey Satellite Data \\
\hline
\end{tabular}

the sensors used in the collected papers are listed in table 5. These satellites are equipped with sensors such as MODIS, TERRA, TIRS, TM, ETM, ASTER, AVHRR, etc. The expansion of each term is listed down in table 6 .

The above given list of satellites and sensors are utilized for the extraction of LST. Remote sensing is employed in finding the land surface temperature, because satellites and the earth is always in motion and capturing the moving air temperature above the ground is a risky task from the point of accuracy.

The available satellite thermal sensors give the temperature data at different spatial resolutions. The spatial resolution varies from kilometers to meters. Commonly used satellites/sensors for the heat island study and their resolutions are given in table 7 .

\subsection{Fixed weather station data}

Meteorological weather station data is another means of finding the temperature in the urban and rural areas. In papers of Mohan et al. (2011, 2012, 2013), Amirtham (2016), Aslam et al. (2017), weather station data is used to analyse temperature in the city, especially for estimating AHI intensity. Mohan et al. (2013) utilized micrometeorological measurements to derive land surface temperatures over 28 locations of Delhi metropolitan city. According to Mohan et al. (2013), fixed weather stations usually provide 
Table 5. Remote Sensing used for UHI study.

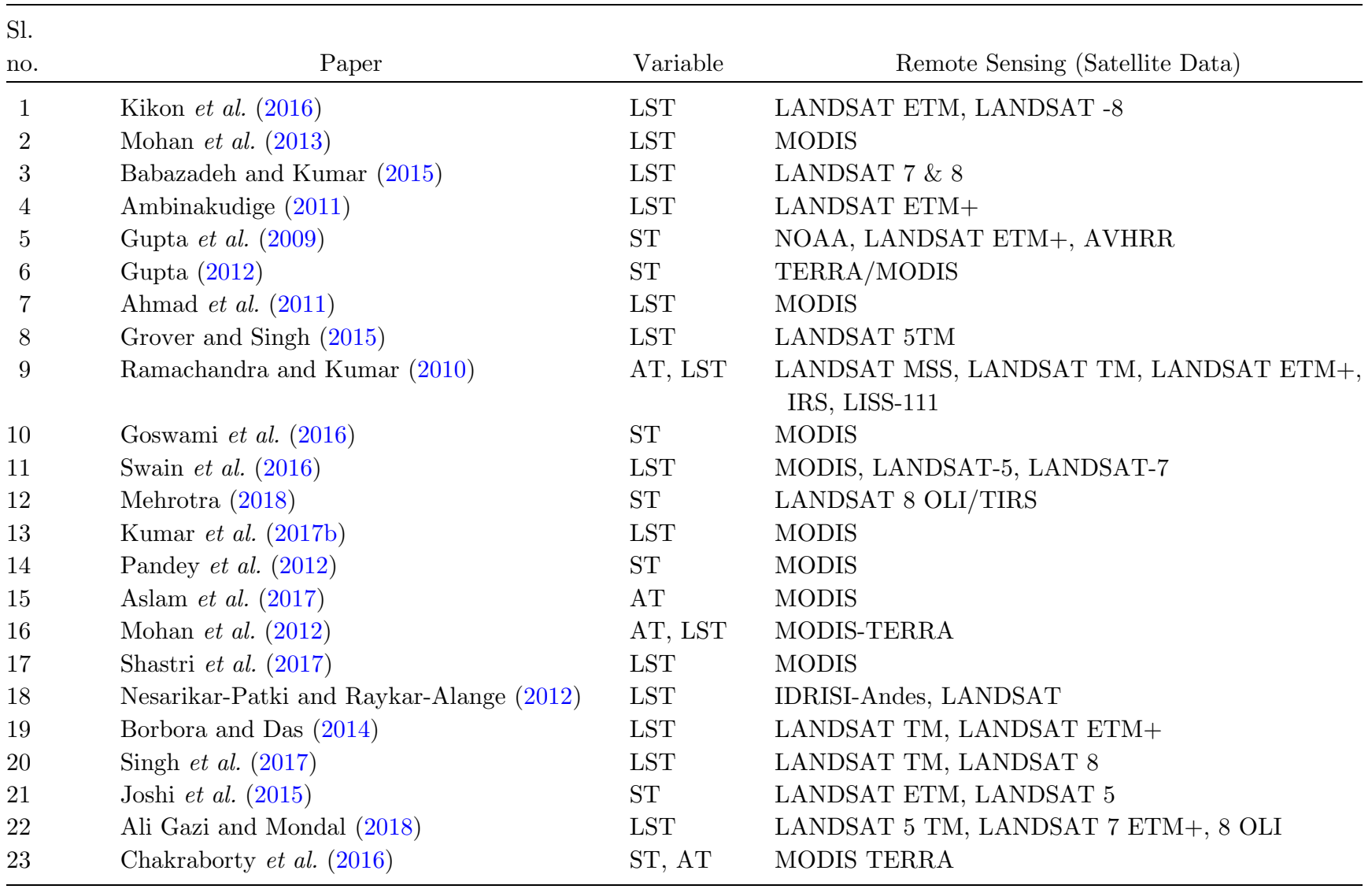

Table 6. Expansion of the terms.

\begin{tabular}{|c|c|}
\hline Abbreviation & Expansion \\
\hline GOES & $\begin{array}{l}\text { Geostationary Operational Environmental } \\
\text { Satellite }\end{array}$ \\
\hline NOAA & $\begin{array}{l}\text { National Oceanic and Atmospheric } \\
\text { Administration }\end{array}$ \\
\hline AVHRR & Advanced Very High Resolution Radiometer \\
\hline MODIS & $\begin{array}{l}\text { Moderate Resolution Imaging } \\
\text { Spectroradiometer }\end{array}$ \\
\hline ASTER & $\begin{array}{l}\text { Advanced Spaceborne Thermal Emission and } \\
\text { Reflection Radiometer }\end{array}$ \\
\hline TM & Thematic Mapper \\
\hline ETM & Enhanced Thematic Mapper \\
\hline MSS & MultiSpectral Scanner \\
\hline OLI & Optical Land Imager \\
\hline TIRS & Thermal Infrared Sensor \\
\hline
\end{tabular}

better temporal resolution of data. Information from four meteorological stations one each at Rohtak, Gurgaon, Palam and Safdarjung are utilized for annual and seasonal mean minimum temperatures in the national capital region of India (Mohan et al. 2011). In another study by Aslam et al. (2017), meteorological data from the two stations in Delhi is collected to assess the seasonal variation of UHI as well as air-quality. Mega city Delhi is analyzed by another group (Mohan et al. 2012) using three weather stations data and compared it with the field campaign and remote sensing information. In order to compute heat intensity in Chennai metropolitan area, the reference data from Nungambakkam meteorological station were utilized by Amirtham (2016).

\subsection{Field survey}

Field measurements can be of two types: Stationary survey (Mohan et al. 2012; Thomas et al. 2014) and mobile survey (Deosthali 2000; Thomas et al. 2014). In stationary survey, a fixed location will be chosen and measures the temperature variation over there using the instruments like thermometers (figure 2). For mobile survey, usually selected routes of different land use types are travelled by a vehicle in which the temperature measuring instruments are already attached. Commonly used instruments to measure heat intensity are Infrared thermometer, Psychrometer, Digital thermometer, RTD probe, Automatic temperature recorders, Max tech Digital thermometer, etc. (table 8). 
Table 7. Satellite versions and its resolution.

\begin{tabular}{rlc}
\hline $\begin{array}{c}\text { Sl. } \\
\text { no. }\end{array}$ & \multicolumn{1}{c}{ Satellite/Sensor } & $\begin{array}{c}\text { Resolution } \\
(\mathrm{m})\end{array}$ \\
\hline 1 & LANDSAT MSS & 60 \\
2 & LANDSAT TM & 30 \\
3 & LANDSAT ETM+ & 30 \\
4 & LANDSAT 4/TM & 120 \\
5 & LANDSAT 5/TM & 120 \\
6 & LANDSAT 7/ETM+ & 60 \\
7 & LANDSAT 8/TIR & 100 \\
8 & GOES & $4 \mathrm{~km}$ \\
9 & NOAA-AVHRR & $1 \mathrm{~km}$ \\
10 & EOS-1 (Terra)/MODIS & $1 \mathrm{~km}$ \\
11 & EOS-1 (Terra)/ASTER & 90 \\
\hline
\end{tabular}

Infrared thermometer, used by Kannamma and Sundaram (2015) and Kumar et al. (2017a), studies on the principle of converting infrared energy focused on a detector to electrical signals and displays the corresponding temperature after manipulation. The details of the instruments used for finding heat island intensity is given in the paper by Sahu et al. (2014).

Like infrared thermometers, digital thermometers are also used to measure temperature (Sharma and Pandey 2015; Baby and Arya 2016). It consists of different types of sensors and the sensor types used are thermocouple, thermistor and resistance temperature detector (RTD). Temperature data loggers usually store temperature measurements over a defined period of time automatically. HOBO data logger, used by Amirtham (2016), consists of integrated sensors for temperature and humidity measurements of outside environment. In HOBO Pro V2 (Borbora and Das 2014), there are weatherproof temperature and humidity data logger with external sensors. Another data logger, called Thermohygro data loggers are used by the The Energy and Resources Institute team (Sastry et al. 2013) to conduct field measurement for

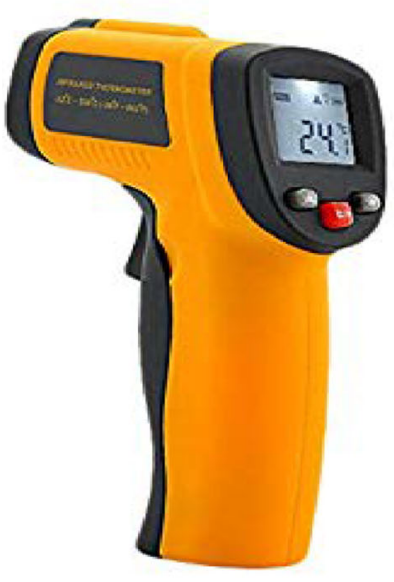

(a) Infrared thermometer

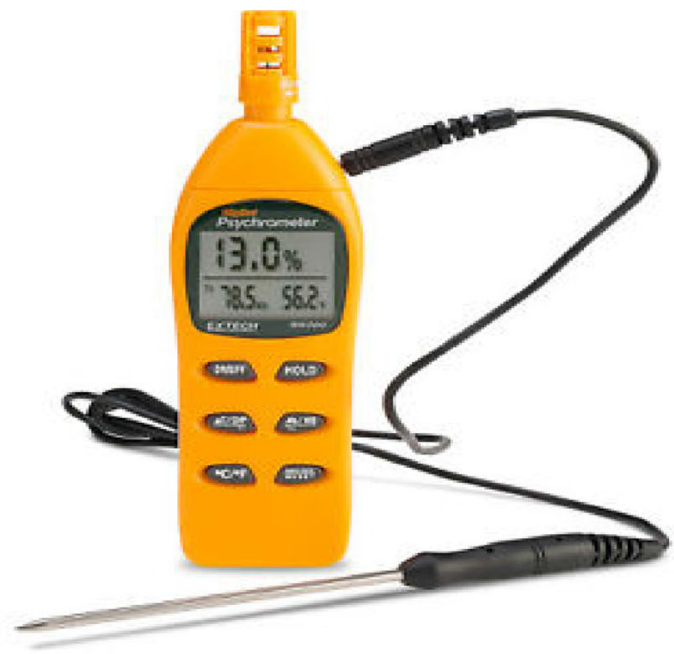

(b) Psychrometer

Figure 2. Instruments used in field survey to measure UHI intensity (from Google images).

Table 8. Instruments used in UHI study.

\begin{tabular}{llll}
\hline $\begin{array}{l}\text { Sl. } \\
\text { no. }\end{array}$ & \multicolumn{1}{c}{ Paper } & Variable & \multicolumn{1}{c}{ Instruments } \\
\hline 1 & Kumar et al. $(2017 \mathrm{a})$ & LST & Infrared thermometer \\
2 & Deosthali $(2000)$ & AT & Psychrometer \\
3 & Kannamma and Sundaram (2015) & PET & Infrared thermometer \\
4 & Baby and Arya (2016) & AT & Digital thermometer \\
5 & Borbora and Das (2014) & AT & HOBO Pro V2, RH Data loggers \\
6 & Thomas et al. $(2014)$ & AT & RTD probe, Automatic temperature \\
& & & recorders \\
7 & Sharma and Pandey (2015) & ST & Max tech Digital thermometer \\
8 & Amirtham $(2016)$ & AT & HOBO Data logger \\
\hline
\end{tabular}


analysing the air temperature at different land use types within Bangalore city.

\subsection{Numerical modelling}

Indian studies are in its preliminary stage in the approach of numerically modelling and analysing the heat island formation in the urban area. This requires proper inputs and high computational facilities. According to the spatial scale, the models are classified as mesoscale and microscale models. In general, a climatic system is an interactive and interdependent system of atmosphere, ocean, land surface, snow and ice. So a general circulation model (GCM) or global climate model is a mathematical model in planetary scale with grid resolution of the order of 100 to $200 \mathrm{~km}$ and consists of basic fluid flow equations that are derived from physical laws in order to simulate the interactions between the atmosphere, ocean, land surface and ice systems. Individual models such as atmospheric model consists of governing equations of atmospheric motions and oceanic model consists of physical and thermodynamic processes in oceans as well as coupled atmospheric and oceanic GCMs called atmosphere-ocean coupled general circulation model is also available. Some developed models are global forecast system (GFS), intermediate general circulation model (IGCM), Varsha GCM, Hadley Centre Coupled Model, version 3 (HadCM3), educational global climate model (EdGCM), etc.

Another subcategory is that the regional climatic models (RCMs) which are the mesoscale models that concentrate on the climatic state over a region or of smaller spatial scale than GCM or a limited area of interest. The large scale processes are considered as boundary conditions for every 3 or $6 \mathrm{hrs}$ to the regional scale model to simulate the climate over a region. One of the most widely used RCM is the Weather Research and Forecasting model, WRF (Aslam et al. 2017). But the local climatic processes cannot be modelled using the mesoscale models. The local climatic changes occur due to the topography of that particular area and many RCMs are not capable to account for these due to coarser spatial resolution. That is, the spatial grid size is larger than the area that covers the effect of localized climatic phenomenon. In such cases a climatic study over a city can be done through microscale models which are having finer grid resolution when compared to mesoscale models.
Significant growth in the development of microclimatic models are occurring since the urbanization impacts are confined to very limited area and climate modelling in the city scale is a much complex task. For these reasons researchers started making use of computational fluid dynamics (CFD) models for simulating the city scale region. CFD is a platform which interconnects mathematics, physics and computation using softwares and are widely used in all scientific and technical fields. There are group of researchers who conduct studies on high-resolution large eddy simulation (LES) models for climate study. In his paper, Marques Filho et al. (2013) analyzed the vertical structure of UHI in the tropical region using LES models. The results show that LES can capture the mesoscale circulation pattern formed due to the surface heterogeneity. Similarly, in another paper Zhang et al. (2013) used the LES of WRF model for simulating the planetary boundary layer features. This is also based on spatial heterogeneity in formation of mesoscale circulation pattern. The domains considered here are in the range of kilometers. When coming down to a scale of within one or two kilometers of domain size, CFD models are highly preferred.

The microscale climatic study using CFD is an emerging field of research globally, but in India CFD urban studies are very limited. In papers by Gopalakrishnan et al. (2003) and Aslam et al. (2017), mesoscale models are used to find the heat patches in south Indian cities and the capital city, respectively. Advanced Research WRF (ARW) model version 3.7 is used in the paper by Aslam et al. (2017) to evaluate diurnal variation of UHI, wind speed and ground heat flux during the months of May and December 2013. The influence of vegetative cover, water bodies and reflective materials in buildings on decreasing the hotspots in the city is analysed by the TERI team (Sastry et al. 2013) using field survey. The results obtained from field measurements are validated using software tools such as ENVI-met. A good correlation was found with the simulated data eventhough it is lower than the measured one.

\section{Results and discussion}

The main classification of UHI study methods are theoretical, observational, experimental and numerical methods. Mills (2014) classified the approaches to the study of urban climate effects in each time period. According to Mills (2014), during 
the year 1900, urban climate effects were observed using conventional meteorological equipments such as thermometers, hygrometers, etc. Then in 1960s, study moved towards measuring the climatic process variables like radiation, sensible and latent heat exchanges. Statistical methods were utilized for analysing the results. Conventional micrometeorological theories were started in 1970s. This is the period when Oke (1973) formulated theories to study urban climates and heat islands. Moreover, computer modelling techniques were slowly initiated during this time. In 1980s, experimental methods were implemented. Small scale physical models of urban forms were made for direct measurement of fluxes. The relationship between real urban forms and real time climate effect were first analysed in 1990s. 21st century gave the breakthrough for urban climate study where development of realistic urban climate models was started. Application of numerical models including CFD came into role for identifying and studying the climate effects in cities. But when Indian climatic studies are concerned, it was initiated in 21st century only and the studies are more based on observational approaches and remote sensing data. The experimental setup of buildings into blocks and analysing the temperature along wind flow patterns are not seen in any of the studies. The research on employing numerical models to the field of climatology is also minimal. Only very few studies of the order of $7 \%$ of the total papers collected includes on numerical models.

Each method has its own advantages and limitations. Theoretically approaching the problem without having definitive profiles of all influencing variables such as temperature, wind velocity, moisture content is almost impossible (Oke 1968). So in general, empirical relations are derived using statistical relations between the important variables. Specification of these variables may in turn require inputs from other methods. Usually it is in the form of prediction of one variable according as a function of another one. This limits the applicability of these simple methods for solving realistic problems (Oke et al. 2017).

Observational approaches include weather station data, instrumental measurement for fixed locations and the mobile surveys. Field measurements were the initial way of UHI study first used by Luke (1818). Advanced instruments present today help to get temperature fluctuation, velocity of air, humidity, solar radiation, precipitation, atmospheric pressure, etc. (Sahu et al. 2014).
However, instrumental measurement either has to compromise on spatial scale or on the temporal scale. The fixed station measurements give the temperature data at the fixed locations (which can be a highest population area or highly marked urban area) where the instruments are fixed permanently. With high resolution instruments, we can measure the temperature for a long time but spatially it is constrained to only a single location. When there is a need for larger spatial coverage more instruments are required and with a network of fixed stations which is again expensive.

Mobile measurements are another way of calculation with larger exposure to the spatial scale, then there the restriction is on the time duration. Because, here space is not fixed but the time of measurement at each location is different and it is not possible to have temperature recordings for whole duration of the day for every location. Another issue with mobile measurement is that if there is no way to account for the movement of sensor relative to the wind flow, then this method is not suitable for wind observations (Oke et al. 2017). Therefore, fixed as well as mobile surveys give data at limited locations and getting the information over a wide range area is time consuming and expensive. The number of variables simultaneously measured are also countable (Mirzaei et al. 2010). Thus, field surveying is not always possible in all the locations at all the time, instruments required to measure temperature and other dependent instruments are again costlier as well. Similarly, in the case of weather station data, the number of stations and information can be collected for a larger spatial area are also limited.

Experimental methods using physical models always approximate the shapes of buildings into blocks and the variation of only a few variables can be analysed. Remote sensing using the satellites is another method widely used in urban studies which can provide very accurate land surface features. But accuracy of the air temperature evaluation away from the surface is not up to the mark. That is, satellite observations can find the land surface and roof of buildings, but it cannot see variation away from the walls and predict the heights of urban structures. So other than land surface temperature, estimating air temperature at higher elevation from the ground cannot be easily predicted with remote sensing (Vogt et al. 1997; Benali et al. 2012). Using land surface temperature, estimation of air temperature at a height of 
$2 \mathrm{~m}$ above the ground which is very adjacent to the surface is possible. But the temperature evaluation within the cities of having high-rise buildings of height above $50 \mathrm{~m}$ cannot be predicted using satellite data. Since air is constantly moving on the land surface, predicting the air temperature spatially and temporally accurate is more difficult. Another factor is that satellite data is helpful when the horizontal land area in hundreds of meters or kilometers. But for a limited area of study in few metres the satellite data cannot be used unless the sensor resolution is very fine.

Numerical models are having better spatial resolution than the satellite data. The spatial scale varies from kilometers to metres. There are mesoscale (large scale of the order of 100s of kilometers) and microscale models (small scale of the order of a few meters) are available now (Mirzaei et al. 2010). One of the indigenous speciality of these models is that this approach helps for predicting the future climate as well. The limitation comes at the validation of these models. It is still in its developmental stage. Without the models are validated with real data, the models cannot be used for urban climate study (Oke 2006). If validated properly, the urban models help a lot in the practical section of planning and changing policies when the knowledge is transferred to the concerned group.

Nowadays, CFD studies are gaining popularity globally due to the fact that they can achieve high spatial resolution compared to other numerical models like mesoscale meteorological model as well as remote sensing data. According to Toparlar et al. (2017), there is a trend of rapid increase in CFD studies of urban microclimate in recent years. They reviewed a total of 183 studies, the earliest study from 1998 to the latest from 2015. As per Toparlar et al. (2017), last three years (2013-2015) constitute more than half of all the studies (104 of 183 studies). Toparlar et al. (2017) review wide range of possibilities of CFD in urban climate study. According to them (Toparlar et al. 2017), to improve predictive capability of CFD simulations the validation of models with measurement data is required in future studies. When the status of Indian climate research is considered, use of CFD in urban climate modelling is in its very preliminary stage. While numerical models are extensively used for pollution dispersion, wind effects and other microclimatic studies, the published studies are not available for the use of CFD models to find temperature distribution in the cities of India.

\section{Conclusion}

In Indian climate studies, satellite data is used more to evaluate urban heat island in the urban and rural areas. Other methods are field measurements, which include instrumental measurements (through mobile surveys and fixed locations) and by accessing weather station data. Numerical modelling is one of the best way to evaluate heat islands and to predict the future climate of the cities. Globally, application of CFD in urban microclimate studies is a trending field of research of 21st century but even now India stands in its preliminary stage. Mesoscale models and CFD models are used for finding pollutant dispersion in the cities, but published studies on heat island studies using numerical models are very rare.

\section{Acknowledgement}

The first author is financially supported by CSIR (Grant No. Ack.No.141410/2K15/1) through Direct SRF Scheme and it is gratefully acknowledged.

\section{References}

Ahmad S, Matloob H, Warsi T R and Khan M D A 2011 The evaluation of heat island effect in various cities in Ganga-Yamuna Doab region using MODIS land surface temperature product; Asian J. Environ. Sci. 6(2) 185-190.

Ali Gazi M A and Mondal I 2018 Urban Heat Island and its effect on Dweller of Kolkata Metropolitan area using geospatial techniques; Int. J. Comput. Sci. Eng. 6 741-753.

Ambinakudige S 2011 Remote sensing of land cover's effect on surface temperatures: A case study of the urban heat Island in Bangalore, India; Applied GIS 7(1) 1-12.

Amirtham L R 2016 Urbanization and its impact on Urban Heat Island intensity in Chennai Metropolitan area India; Indian J. Sci. Technol. 9(5).

Aslam M Y, Krishna K R, Beig G, Tinmaker M I R and Chate D M 2017 Seasonal variation of Urban Heat Island and its impact on air-quality using SAFAR observations at Delhi, India; Am. J. Clim. Change 6(02) 294-305.

Babazadeh M and Kumar P 2015 Estimation of the Urban Heat Island in local climate change and vulnerability assessment for air quality in Delhi; Eur. Sci. J., 55-65.

Baby M M and Arya G 2016 A Study of Urban Heat Island and its mapping; Int. J. Sci. Eng. Res. 4(3) 45-47.

Benali A, Carvalho A, Nunes J, Carvalhais N and Santos A 2012 Estimating air surface temperature in Portugal using MODIS LST data; Remote Sens. Environ., 108-121.

Blocken B 2015 Computational Fluid Dynamics for urban physics: Importance scales possibilities limitations and ten tips and tricks towards accurate and reliable simulations; Build. Environ., 1-27. 
Borbora J and Das A K 2014 Summertime Urban Heat Island study for Guwahati City, India; Sustain. Cities Soc. 11 61-66.

Chakraborty T, Sarangi C and Tripathi S N 2016 Understanding diurnality and inter-seasonality of a sub-tropical Urban Heat Island; Bound.-Layer Meteorol., https://doi. org/10.1007/s10546-016-0223-0.

Deosthali V 2000 Impact of rapid urban growth on heat and moisture Islands in Pune City, India; Atmos. Environ. 34 2745-2754.

Devi S S 2006 Urban Heat Islands and environmental impact; 6th Symposium on the Urban Environment and Forum on Managing our Physical and Natural Resources.

Gopalakrishnan S G, Rama Krishna T V B P S and Sharan M 2003 Some signatures of Urban Heat Patches in southern India; Proc. Indian Natl. Sci. Acad. 5 603-614.

Goswami A, Mohammad P and Sattar A 2016 A temporal study of Urban Heat Island (UHI) - A evaluation of Ahmedabad city, Gujarat; International Conference on Climate Change Mitigation and Technologies for Adaptation, pp. 1-5.

Grover A and Singh R B 2015 Analysis of Urban Heat Island (UHI) in relation to Normalized Difference Vegetation Index (NDVI): A comparative study of Delhi and Mumbai; Environments 2 125-138.

Gupta A, Dey V and Goel D A 2009 Mitigation of thermal pollution to enhance urban air quality through Remote Sensing and GIS; 10th ESRI India User Conference.

Gupta R 2012 Temporal and spatial variations of Urban Heat Island effect in Jaipur City using satellite data; Environ. Urban. Asia 3(2) 359-374.

Jain G and Sarkar S 2017 Urban Heat Island: Causes effects and mitigating strategies; Imp. J. Interdiscip. Res. 3(5) 2098-2103.

Joshi R, Raval H, Pathak M, Prajapati S, Patel A, Singh V and Kalubarme M H 2015 Urban Heat Island characterization and isotherm mapping using geo-informatics technology in Ahmedabad City, Gujarat State, India; Int. J. Geosci. 6 274-285.

Kannamma D and Sundaram D A M 2015 Significance of microclimatic study in Urban Canyons towards ambient urban space design; J. Today's Ideas - Tomorrow's Technol. 3(1) 95-109.

Kikon N, Singh P, Singh S K and Vyas A 2016 Assessment of urban heat islands (UHI) of Noida City, India using multitemporal satellite data; Sustain. Cities Soc. 22 19-28.

Kratzer A 1937 Das Stadtklima.

Kratzer A 1956 The Climate of Cities (Das Stadtklima).

Kumar R and Singh S 2016 Case study for change detection analysis and land surface temperature retrieval in Uttrakhand Region and their correlation; Imp. J. Interdiscip. Res. 2(9) 1821-1825.

Kumar K S, Udaya Bhaskar P and Kumari K P 2017a Assessment and mapping of urban heat island using field data in the new capital region of Andhra Pradesh, India; Indian J. Sci. Technol. 10(11) 1-8.

Kumar R, Mishra V, Buzan J, Kumar R, Shindell D and Huber M 2017b Dominant control of agriculture and irrigation on Urban Heat Island in India; Sci. Rep., 1-10.

Landsberg H E 1981 The Urban Climate; Int. Geophys., 28.

Luke H 1818 The climate of London deduced from meteorological observations made at different places in the Neighbourhood of the Metropolis; 1p.
Marques Filho E P, Cassol M A, Karam H and Rizza U 2013 The vertical structure of Tropical Urban Heat Island with LES; Am. J. Environ. Eng. 3 24-31.

Mehrotra S 2018 Urban informal housing and surface Urban Heat Island intensity: Exploring spatial association in the city of Mumbai; Environ. Urban. Asia 9(2) 1-20.

Mills G 2008 Luke Howard and The Climate of London; Weather 63(6) 153-157.

Mills G 2009 Luke Howard, Tim Oke and the study of urban climates; Eighth Symposium on the Urban Environment.

Mills G 2014 Urban climatology: History, status and prospects; Urban Clim. 10 479-489.

Mirzaei P A and Haghighat F 2010 Approaches to study Urban Heat Island - Abilities and limitations; Build. Environ. 45 2192-2201.

Mohan M, Kandya A and Battiprolu A 2011 Urban Heat Island Effect over national capital region of India: A study using the temperature trends; J. Environ. Prot. 2 465-472.

Mohan M, Kikegawa Y, Gurjar B R, Bhati S and Reddy Kolli N 2013 Assessment of Urban Heat Island effect for different land use-land cover from micrometeorological measurements and remote sensing data for megacity Delhi; Theor. Appl. Climatol. 112 647-658.

Mohan M, Kikegawa Y, Gurjar B R, Bhati S, Kandya A and Ogawa K 2012 Urban Heat Island assessment for a Tropical Urban Airshed in India; Atmos. Clim. Sci. 2 127-138.

Nakata-osaki C M, Lucas de Souza L C and Rodrigues D S 2015 A GIS extension model to calculate Urban Heat Island intensity based on urban geometry; Comput. Urban. Plan. Urban. Manag., 1-16.

Nesarikar-Patki P and Raykar-Alange P 2012 Study of inuence of land cover on Urban Heat Islands in Pune using remote sensing; IOSR J. Mech. Civil Eng. 3 39-43.

Oke T R 1968 Sustainable urban development: Minimising Urban Heat Island effect and imperviousness factor; pp. 1-20.

Oke T R 1973 City size and the Urban Heat Island; Atmos. Environ. 7 769-779.

Oke T R 2006 Towards better scientific communication in urban climate; Theor. Appl.Climatol. 84 179-190.

Oke T R, Mills G, Christen A and Voogt J A 2017 Urban Climates.

Pandey P, Kumar D, Prakash A, Masih J, Singh M, Kumar S, Jain V K and Kumar K 2012 A study of Urban Heat Island and its association with particulate matter during winter months over Delhi; Sci. Total Environ. 414 494-507.

Ramachandra T V and Kumar U 2010 Greater Bangalore: Emerging Urban Heat Island; GIS Develop. 14(1) 1-16.

Sahu S, Pawar A and Mukherjee M 2014 Urban Heat Island investigation: Techniques and methods so far; Architecture - Time Space \& People, pp. 16-22.

Sastry M, Majumder M, Kumar P and Kiran Kumar D E V S 2013 Sustainable urban development: Minimising Urban Heat Island effect and imperviousness factor; Sanei Working Paper Series, 13-03.

Sharma D and Bharat A 2009 Urban Heat Island effect causes impacts methods of measurement and mitigation options; Institute of Town Planners, India 6(2) 69-77.

Sharma N and Pandey P 2015 Study of Urban Heat Island in Bathinda City, Punjab; 16th ESRI India User Conference, pp. 1-14. 
Shastri H, Barik B, Ghosh S, Venkataraman C and Sadavarte P 2017 Flip flop of Day-night and Summer-winter Surface Urban Heat Island intensity in India; Sci. Rep. - Nature $1-8$.

Singh P and Kikon Noyingbeni Verma P 2017 Impact of land use change and urbanization on Urban Heat Island in Lucknow city, Central India: A remote sensing based estimate; Sustain. Cities Soc. 32 100-114.

Swain D, Roberts G J, Dash J, Vinoj V, Lekshmi K and Tripathy S 2016 Impact of rapid urbanization on the microclimate of Indian cities: A case study for the city of Bhubaneswar; Proc. SPIE 9877 1-7.

Corresponding editor: Amit Kumar Patra
Thomas G, Sherin A P, Ansar S and Zachariah E J 2014 Analysis of Urban Heat Island in Kochi, India, using a modified local climate zone classification; Procedia Environ. Sci. 21 3-13.

Toparlar Y, Blocken B, Maiheu B and van Heijst G 2017 A review on the CFD analysis of urban microclimate; Renew. Sust. Energ. Rev., 1-28.

Vogt J V, Viau A A and Paquet P F 1997 Mapping regional air temperature fields using satellite-derived surface skin temperature; Int. J. Climatol., 1559-1579.

Zhang N, Wang X and Peng Z 2013 Large-Eddy simulation of mesoscale circulations forced by inhomogeneous Urban Heat Island; Bound.-Layer Meteorol., 179-194. 